\title{
Productivity and Indoor Environmental Conditions Research: An Annotated Bibliography for Facility Engineers
}

by

Debra Brinegar Lister

Elisabeth M. Jenicek

Paul Fredrick Preissner

\begin{abstract}
Since the energy crisis in the mid-1970s to the renewed interest in reducing the nation's energy consumption, conservation strategies often have been employed with little regard to their impact on the occupants of the affected buildings. Austere conditions created by the overly zealous mentality that pervaded the facility engineering community in the seventies made building occupants quite uncomfortable and affected their productivity. Today, energy conservation and efficiency-improving measures are again being implemented, but with more emphasis on finding ways to conserve energy while creating comfortable and productive work environments. This annotated bibliography summarizes past and current research that addresses how environmental conditions impact the comfort, workplace satisfaction, and productivity of building occupants. It is intended as a resource to help inform the decisions of facility engineers and managers in the development and implementation of energy conservation strategies.
\end{abstract}





\section{Foreword}

This study was conducted for the Directorate of Military Programs, Heat quarters, U.S. Army Corps of Engineers (HQUSACE), under Project 4A162784AT45, "Energy Technology Applied to Military Fadilities"; Work Unit FLE-X78, "Energy Efficiency and Productivity." The HQUSACE technical mopitor

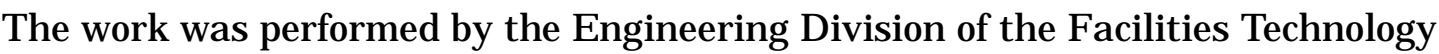
Laboratory, U.S. Army Construction Engineering Research Laboratories (USACERL). The USACERL Principal Investigator was Debra Brinegar Lister. Larry M. Windingland is Chief, CECER-FL-E, and L. Michael Golish is Acting operations Chief, CECER-FL. The USACERL technical editor was Vicki A. Rei hhart, Technical Information Team.

CO J ames A. Walter is the Commander of USACERL, and Dr. Michael o'connor is the Director. 


\section{Contents}

SF 298.............................................................................Error! Bookmark not defined.

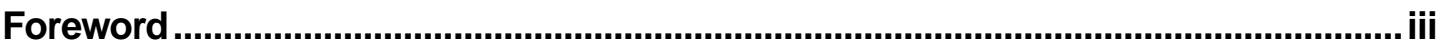

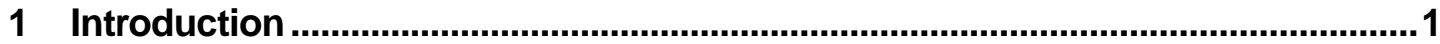

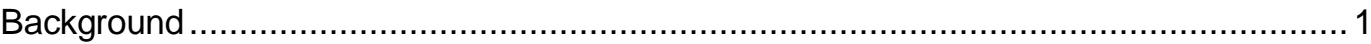

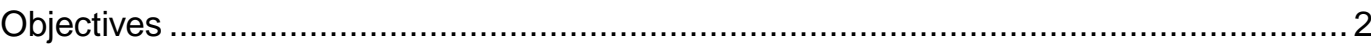

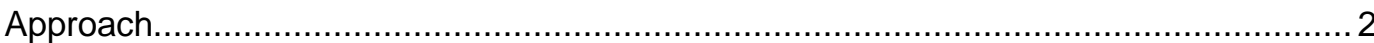

2 Overview of Indoor Environmental Quality Issues................................................

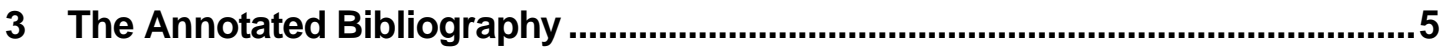

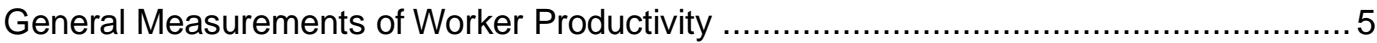

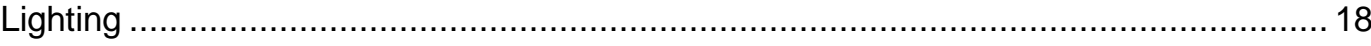

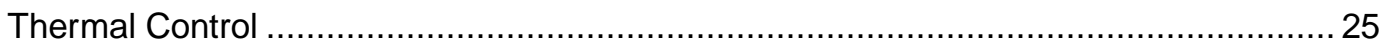

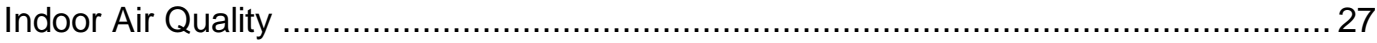

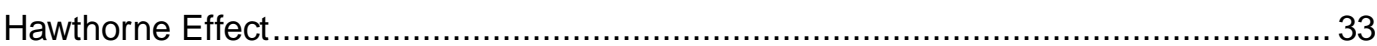

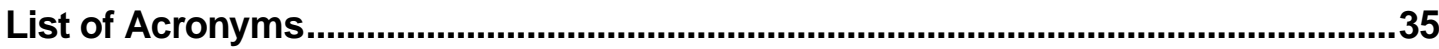

Distribution 


\section{Introduction}

\section{Background}

From the first energy crisis in the mid-seventies to the current renewed interest in reducing the nation's energy consumption, conservation strategies have been employed with little regard to their impact on the end user. Temperature reductions have been strictly enforced. A decade ago it was not atypical to find locked thermostats or, in more occupant friendly systems, dummy thermostats. Outside air dampers were sealed to reduce heating and cooling loads, contributing to poor indoor air quality. Reduced lighting energy use was accomplished by indiscriminately disconnecting fluorescent lamps or entire fixtures. With the advent of energy saver 34W lamps, F 40T12 lamps were replaced wholesale with little regard for the resulting 15 percent loss in light level.

As building technology caught up with stringent energy reduction targets, achieving lower levels of energy use was possible while maintaining comfort for the building occupants. I mproved motors, and advances in window glazing and electronic circuitry have done much to reduce both the financial and personal costs of energy efficiency. Selling energy projects on the basis of life-cycle costing improved their funding and execution. However, the impact on worker productivity has not been quantified in the cost formula.

The impact of poor indoor environmental quality on workers is estimated as high as billions of dollars a year nationwide (Woods 1989). A slight increase in productivity, seen as decreased absenteeism or increased attentiveness, may be very cost-effective.

Army construction and renovation projects are designed to achieve the lowest life-cycle cost, but the impact of building systems on worker productivity is not considered as part of the building's life-cycle cost. This work attempts to quantify the productivity impact of energy-efficient lighting and heating, ventilation, and air conditioning (HVAC) systems and to develop guidance for incorporating the findings into building design criteria. 


\section{Objectives}

The objective of this report is to provide information on past and current research performed in the area of indoor environmental conditions and the impact on the productivity of building occupants.

\section{Approach}

During fiscal years 1995 and 1996, efforts concentrated primarily on gathering information from previous research into the impact of building systems on worker productivity. A literature search was conducted using the computerized index of the University of Illinois at Urbana-Champaign, the Internet, and recommendations from experts in the fields of lighting, thermal control, indoor air quality, and experimental design and analysis. Useful references were compiled in an annotated bibliography of citations and synopses. 


\section{Overview of Indoor Environmental Quality Issues}

Historically, productivity research has concentrated on repetitive, mass-produced product-oriented fields of work. Measuring productivity was accomplished by measuring the amount or quality of product generated. Gauging productivity of office workers has been a challenge. Documented measures for productivity studies include (1) output: quantity/rate, quality/accuracy, and cost/efficiency; (2) withdrawal: turnover, absenteeism, and tardiness; and (3) disruptions: accidents/ safety, strikes, slowdowns, grievances, and alcohol/drugs (Guzzo 1983). Occupant questionnaires have been used extensively. The questionnaires ask the occupant to rate the building system in terms of desirability and how well it supports the work effort. Worker productivity experiments have been conducted in simulated offices in laboratory settings, as well as in operational buildings.

Previous research on lighting effectiveness decries the use of foot-candle ratings alone as a design criteria. Evidence was presented to support criteria such as luminance ratios, surface brightness, and glare-especially where visual display terminals (VDTs) are present. Lower ambient lighting levels with occupantcontrolled task lighting can achieve lower lighting power densities than typical $2 \times 4$ grid lensed troffer systems. Although the eye is able to perform under many lighting conditions, some conditions cause discomfort and dissatisfaction and can result in reduced productivity. Discomfort, glare, reflected glare, and veiling reflections cause eyestrain and headaches. The "cave effect," bright ceilings with dark walls, makes an unappealing work space and can lower morale.

In attempts to meet the guidelines of the American Society of Heating, Refrigerating, and Air-Conditioning Engineers (ASHRAE) 55-1992, designers acknowledge that up to 20 percent of building occupants will be dissatisfied. Typical HVAC systems lack the zones and/or control systems to bring thermal discomfort to a minimum. Systems designed with the best intentions can lose effectiveness because of lack of maintenance. Under-floor task ventilation composed of individual fan modules controlled by workstation occupants received high marks from managers and workers (Hedge 1993). In the West Bend Mutual Insurance Company's new headquarters, occupant-controlled temperature coupled with occupancy sensors that automatically turn the systems off when spaces are unoccupied, reduced el ectricity costs by 38 percent (Beck 1993). Most 
references cite the need for stringent field measurements to accurately characterize and evaluate HVAC systems.

Indoor air quality (IAQ) has suffered greatly from the desire to minimize energy consumption by reducing outside ventilation air. The increased use of equipment such as laser printers and photocopiers has generated increased contaminants. Although ASHRAE 62-1989 is intended to provide ventilation standards for maintaining satisfactory IAQ, litigation has shown that adherence to the standard does not relieve building designers, owners, or operators from the obligation to provide a safe working environment.

The Hawthorne Effect is recognized as a potential influence in the field trial portion of research. This effect suggests that any workplace change, including a research study, makes people feel important and thereby improves their performance. Literature discussing the relevance of this effect in experimental design was reviewed in order to sensitize the Principal Investigators to this extraneous variable and to make allowances for it during any field trials. 


\section{The Annotated Bibliography}

The annotated bibliography is divided into five sections: General Measurements of Worker Productivity, Lighting, Thermal Control, Indoor Air Quality, and the Hawthorne Effect.

\section{General Measurements of Worker Productivity}

Anderson, J ames R., and Sue Weidemann, "Evaluating Office Environments Volumes 1-5,"

H ousing Research and Development Program, Urbana, IL: University of Illinois (1992).

Abstract: This report describes a study designed to test an exploratory model predicting respondent's self-reports of their productivity and satisfaction with their work. Volumes I and II contain the original questionnaire, as well as a set of objective measurements of characteristics of the physical environment used to test the model. Volume III is a comparative analysis of the workers' perceptions of the workspace with the objective measurements. Volume IV begins with the results of an analysis intended to synthesize selected material from the first three volumes. The final volume contains the data charts.

Anderson, J ., S. Weidemann, D. Heinen, B. Adeoye, and S. Beazly, "Evaluating Office Environments: A Case Study," U.S. Army Corps of Engineers (May 1994).

Abstract: This report describes a case study of the renovation of an office building. This study is separated into three steps: analysis prior to redesign, redesign of environment, and analysis after the renovation. Conversations, site visits, a survey, and a refined questionnaire were used to determine the user's perception of quality, satisfaction, and productivity before the renovations took place. The employees completed the same questionnaire after the renovation. The questionnaire asked about more than 22 characteristics related to workstation satisfaction. Employees perceived many changes after the renovation was completed. This report discusses those changes and maps out how the method of renovation was initiated or determined. 
Army, Department of the "Army Regulation (AR) 5-4, Department of theArmy Productivity Improvement Program," Washington, DC (1982).

Abstract: This regulation establishes the Department of the Army Productivity Improvement Program (DAPP) with the following objectives: achieve optimum productivity improvement; reduce the overall cost of Army operations, supplies, and services; provide a capability for improving management and operating practices throughout the Army; stimulate the initiation of productivity improvement actions; and attain the highest possible level of Army readiness with available resources.

Aronoff, S., and A. Kaplan, Total Workplace Performance: Rethinking the Office Environment, (WDL Publications, 1995).

Abstract: This book defines the workplace, its operation, and how it impacts the people who work there. It looks at the origins of modern day offices in terms of function, systems, and interior settings as well as affects on human performance. This discussion relies on practical implications and choices that can significantly enhance the value an organization realizes from its office facility.

Beck, Paul E., “Intelligent Design Passes IQ Test," Consulting-Specifying Engineer, pp 34-38 (J anuary 1993).

Abstract: This article describes the integrated intelligent design encompassed in West Bend Mutual Insurance Company's new 150,000-sq ft headquarters building in West Bend, WI. An independent study conducted by the Center for Architectural Research and the Center for Services Research and Education at Rensselaer, Troy, NY, demonstrated that the integrated systems within the building not only improved occupant comfort, but also led to a productivity increase that paid for the systems in less than one year. At the heart of the building's design is an air distribution system known as "environmentally responsive work stations" and the distributed direct digital control building automation system that ties together HVAC, security, and fire protection systems. Occupants in open-office areas control the airflow within their spaces through vents and radiant heaters built into furniture. Air is distributed via an under-floor plenum that reduced the number of variable air volume (VAV) boxes and ductwork, and allowed flexibility for electrical and communications wiring. An ice-storage system was installed to lower electrical costs. Though heating is electrical, the diversity in temperatures between work stations and the use of occupancy controls that automatically turn off the system when spaces are unoccupied reduced the building's overall electricity costs to $\$ 0.11$ per sq $\mathrm{ft}$ compared to the previous building's $\$ 0.18$ per sq ft. Energy used for lighting is 1.7 watts per sq ft with a resultant reduction in cooling loads. Total system cost 
was only 8 percent above that of a conventional design. Utility incentive programs kept the project within a $\$ 90 /$ sq $\mathrm{ft}$ budget, despite the high level technology used.

Biner, P., B. Darrell, T. Lovegrove, and R. Burns, "Windowlessness in the Workplace: A

Reexamination of the Compensation Hypothesis," Environment and Behavior, vol 25, no. 2

(March 1993).

Abstract: This artide examines how workers in windowless environments find surrogate windows in their work area. Experiment 1 had students rate the degree to which they perceived various office features to be window substitutes. Analyses revealed four potential window substitutes: other apertures (e.g., skylights), paintings/art, living things (e.g., plants), and panels (e.g., lighting panels). Experiment 2 supported the external validity of Experiment 1 data that full-time workers produced virtually identical ratings of window substitutability. Experiment 3 was a field study of 173 offices in which measurements and data of windows, offices, locations, etc., were taken as well as data on potential window substitutes. No evidence was recorded to show any surrogates were more prevalent in windowless offices than in windowed offices. Experiment 4 investigated other potential reasons for use of the surrogate items found in Experiment 3.

Center for Building Performance and Diagnostics, "DoE Building Studies," Carnegie Mellon University, Pittsburgh, PA (1994).

Abstract: The artide evaluates occupant response to Department of Energy (DoE) buildings.

Collins, Belinda L., and Arthur I. Rubin, "Analysis of Work Environment Data from Three Army Field Stations," National Institute of Standards and Technology, Gaithersburg, MD, NISTIR 88-3871 (October 1988).

Abstract: This report presented data from a detailed evaluation of environmental conditions in three U.S. Army field stations: Kunia, Hawaii; Augsburg, Germany; and Berlin, Germany. A questionnaire was administered to over 600 people at all three sites. Questionnaire results indicate major concerns with conditions such as temperature, lighting, space, furniture, equipment functioning, and general environmental quality. Physical data obtained from measurements of more than $\mathbf{2 7 0}$ workstations indicated cold temperatures, low light levels, reduced VDT screen contrast, glare, and distracting noises. The report provides the basic data that supports the concern expressed by U.S. Army Intelligence and Security Command Headquarters that field station personnel perform their jobs under conditions likely to impair their effectiveness. 
Suggestions for improving these conditions are given in a companion report by Rubin and Collins.

Collins, Belinda L. et al., "Post-Occupancy Evaluation of Several U.S. Government Buildings," National Institute of Standards and Technology, Gaithersburg, MD, NISTIR 89-4175 (September 1989).

Abstract: A post-occupancy evaluation (POE) was performed on five small, lowrise U.S. Government office buildings at a site south of Washington, DC. The study recorded occupant response to indoor environmental conditions including lighting, space, noise, and IAQ; and provided recommendations for improvements to the facilities. In addition, a comparison was made of environmental conditions before and after renovation of one of the buildings. A total of 308 people participated and physical measurements were taken at 92 workstations. Analysis of the physical measurement data indicated problems with limited space, lack of adjustable task lighting, and perceptions of poor IAQ in two of the buildings. The renovation was perceived to have substantially improved the appearance of one building. Suggestions for improvements to other buildings at the site were also made.

Drezner, J ., and M. Bradley, "A Survey of DoD Facility Energy Management Capabilities," National Defense Research Institute, Report MR-875-OSD, RAND Corp. (1998).

Abstract: The Department of Defense (DoD) is the largest single user of energy in the nation. Management of that energy is not a primary concern, however, it can contribute to readiness and sustainability goals, as well as cost savings. This document details the structure and difficulties in the present methods. This is part of a larger effort to examine the issues of energy and facility management at DoD installations.

Edwards, Steve, "How to Balance Needs of Workers and Equipment," Office Systems, vol 7, no. 9 (1990).

Abstract: This article discusses the design of systems furniture in an open area workstation configuration with an emphasis on ergonomics. A compact workstation with sufficient work space and maximum comfort is desirable. Office lighting should be a product of quality, rather than quantity. The difference in cost to outfit an employee with an ergonomic desk, chair, and storage area, as opposed to nonadjustable furniture is minimal, but the payback is significant. Even a slight increase in productivity justifies the cost of corrective furnishings. 
Fisk, William, "Improved Productivity and Health From Better Indoor Environments: A Research Initiative," Indoor Environment Program, Lawrence Berkeley Laboratory (1994).

Abstract: This research initiative suggests five links between the quality of indoor environment, and health and productivity. These links include: infectious disease, allergies and asthma, acute sick-building health symptoms, worker performance, and electronic equipment failures. The author proposes a multidisciplinary, multi-institutional program to study these links, evaluate methods to improve indoor environment, quantify the benefits and costs of improvements, and use technology transfer to promote adoption of the measures. The author suggests research elements, required scientific expertise, and government and industry roles. He also provides cost estimates for the recommended research.

Guzzo, Richard A., and J effrey S. Bondy, A Guideto Worker Productivity Experiments in the United States, 1976-81 (Pergamon Press Inc. 1983).

Abstract: This book presents the findings of 104 experiments in advancing worker productivity documented between 1976 and 1981. The book defines 14 measures intended to improve productivity and 14 criteria for measuring productivity. The experiments are summarized in table form by the intervention programs contained in each. An abstract of each experiment is contained in the book. The authors located no reports of experiments involving improved physical working conditions published during this timeframe. They state that not all productivity experiments published met the criteria for indusion in this review and that some eligible research reports could have been unintentionally omitted.

Heinen, D., R. Rundus, M. Kemme, R. Nemeth, G. Kinzer, K. Quinlan, B. Adeoye, and B. Rives, "How Building Systems Affect Worker Wellness," U.S. Army Corps of Engineers (March 1994).

Abstract: This study looks at how individual building traits or deficiencies affect the individual worker's performance. Qualities such as thermal comfort, IAQ, lighting performance, and spatial configuration are analyzed. This study created a database for connecting tangible physical/environmental adjustments with human health, performance, and satisfaction.

I vanovich, M., J . Wise, D. J antrip, and J . Heerwagen, "Status on the Development of a Protocol for Assessing Potential Benefits of Green Buildings," Pacific Northwest Laboratory, Richland, WA, (n.d.).

Abstract: This paper describes an effort to develop a general protocol for assessing the environmental benefits of Green Buildings. The purpose of Green Buildings is to minimize their environmental impacts. Standard evaluation is done by a checklist. The checklists do not analyze the effects these buildings will have on the occupant's productivity, or the overall positive and negative impacts 
changes in the building's future operation and maintenance (O\&M) may have. The purpose of this effort is to begin to develop that analysis.

Kroner, W., J . Stark-Martin, and T. Willemain, "Using Advanced Office Technology to I ncrease Productivity," Rensselaer Polytechnic Institute (1992).

Abstract: This is the much referenced study of the West Bend Mutual (WBM) Insurance Company in West Bend, WI. This consisted of a 27-week observation and data collection study of the WBM, beginning on $2 \mathrm{~J}$ anuary 1991 . In J uly of that year, the employees moved to a new office building and provided the researchers with 24 weeks for observations there. Overall, there were 51 weeks of data collection over the time span of $2 \mathrm{~J}$ anuary through 20 December 1991. This study provided important information about the influence of personal climate control on individual productivity. The study also gave insights on the affects of architectural design and personal environment on office productivity.

Loftness, V., V. Hartkopf, S. Lee, and A. Mahdavi, "Smart Buildings: Tomorrow's I ntelligent Buildings Will MergeAdvanced Technologies and Environmental Responsiveness Through Team Design Processes and User-Based Facilities Management," Department of Architecture, Carnegie Mellon University (1994).

Abstract: The definition of "smart" buildings must move beyond the long list of new products in telecommunications, electronics, and control systems to include a comprehensive definition of the productive high-tech work environments needed by the occupants of the buildings. Existing mechanical and electrical infrastructures are incapable of accommodating the rapidly changing organizational and technological requirements for buildings today. The new definition must focus on the quality of the environment of the user or individual.

Loftness, V., V. Hartkopf, S. Lee, A. Mahdavi, J . Shankavaram, and K. Tu, “The Relationship of Environmental Quality in Buildings to Productivity, Energy Effectiveness, Comfort, and Health - How Much Proof do We Need?," Department of Architecture, Carnegie Mellon University (1994).

Abstract: Given the standards of acceptability today, increasing environmental quality and user control in the workplace are critical goals for the United States. User control of environmental conditions offers a great opportunity to ensure indoor environmental quality for the individual, especially in the face of rapid changes in technology, organizational structure, and work hours. Moreover, user control of environmental conditions can offer cost and energy savings with economic benefits for both employer and employee.

Loftness, V., V. Hartkopf, S. Lee, A. Mahdavi, A. Aziz, and P. Mathew, “Environmental Consciousness in the Intelligent Workplace," Department of Architecture, Carnegie Mellon University (1994). 
Abstract: This is a presentation of research into the major design changes in office environments and the construction of a living laboratory for in-depth studies of evolution in enclosure, mechanical, electrical, telecommunications, and interior systems, as well as their integration to create high performance work environments.

Loftness, V., V. Hartkopf, K. Lam, and A. Mahdavi, "Simulation-Based Performance Evaluation as a Design Decision Support Strategy: Experiences with the 'Intelligent Workplace',"

Department of Architecture, Carnegie Mellon University (1993).

Abstract: Application of geometric modeling and various performance simulation tools in architectural design are presented along with highlights of impact on the design decisions made. Based on the experiences gained in this process, a critical review of the potentials and problems of current simulation tools and simulation-based design decision-making strategies is offered. Particular attention is given to the crucial dialectic of process and tool in supporting knowledge transfer and decision-making in building design. Suggestions for improvements to current performance simulation tools and future alternative building simulation environments are discussed.

Lomonaco, C., and D. Miller, "Environmental Satisfaction, Personal Control and the Positive Correlation to Increased Productivity," J ohnson Controls (1997).

Abstract: This study by J ohnson Controls documents the relationship between environmental comfort, workplace productivity, and individual environment control. Information is presented concerning how the nature or condition of workers' individual environment has positive or negative effects on productivity. Examples of previous studies are used to support the daim that indoor environment is a strong determinant of how high or low individual productivity rests. In addition, this report presents methods to achieve individual control through indoor environment technology advances.

Lovins, Amory B., "Better Buildings by Design," Strategic Planning for Energy and the Environment, vol 14, no. 3 (1992).

Abstract: This article examines the efficiency problems of a building using a checklist of symptoms with methods for solutions. Categories included on the checklist are: lighting schemes, fixtures, IAQ, and other general environmental concerns.

Lovins, Amory B., "Energy-Efficient Buildings: Institutional Barriers and Opportunities," E Source Inc. (1992). 
Abstract: Buildings are rarely built to use energy efficiently, despite the sizable costs that inefficient designs impose. This is due to the institutional framework within which buildings are financed, designed, constructed, and operated. Many of the participants in this process have incentives that reward inefficient practice. Fragmented and commoditized design, false price signals, and substitution of obsolete procedures for true engineering optimization have resulted in buildings that cost more to build, are less comfortable, and use more energy than they should. Investments in design education, leasing reform, elimination of the wrong incentives for designers and engineers, and support of building commissioning and operation offer opportunities to achieve important benefits quickly. In response to these opportunities, a "second generation" of utility Demand Side Management (DSM) programs is beginning to emerge, incorporating new approaches such as direct incentives for building designers. Also, the ability to build and operate buildings with the best energy design features is an increasingly important competitive factor for building owners and developers.

Mundel, Marvin E., The White-Collar Knowledge Worker: Measuring and Improving Productivity and Effectiveness (Asian Productivity Organization, 1989).

Abstract: This book describes an approach and personal computer program that makes the measurement and improvement of the productivity and effectiveness of white-collar knowledge workers both feasible and practical. The book indudes an IBM/DOS compatible computer program (written in BASIC language on a floppy disk) that facilitates the measurement of work and productivity. The author states that the materials in this book have been used successfully with real organizations. For each example, work units are defined and a discussion of work measurement follows. Most of the book is devoted to software instructions and documentation. It includes chapters on improving productivity and improving effectiveness.

Nemecek, J ., and E. Grandjean, "Results of an Ergonomic Investigation of Large-Space Offices," Human Factors, vol 15, no. 2 (1973).

Abstract: Ergonomic measurements of noise, lighting, and room climate were made in fifteen large-space offices in Switzerland. Concurrently, 519 employees completed a questionnaire about working in the offices. Questions covering continuation of work, distractions, disturbances, interpersonal relations, and communications were included. The correlations indicated some factors have special influence on the operation of the large-space office. The results form an objective, usable decision base for selection and planning of an office building. 
Abstract: This article discusses the work of the Cornell International Facility Management Program (IFMP). Since its creation in 1989, the IFMP has studied innovative office facilities in the United States, England, Europe, and J apan to determine how they can help companies reduce costs, increase productivity, and enhance employee satisfaction. One fact IFMP discovered is in many companies up to 70 percent of the workforce may be away from the office at any given time, resulting in costly unused workspace. Technology is another factor shaping the modern office. The availability of smaller and more powerful computers, modems, fax machines, and other technologies now allow people to communicate from almost anywhere. The IFMP also found that people are more productive and communicate more effectively when they are comfortable. These facts suggest the use of satellite offices or work-at-home scenarios.

Romm, J oseph J ., Lean and Clean Management: How to Boost Profits and Productivity by Reducing Pollution (Kodansha America, Inc., 1994).

Abstract: Using case studies, a recommendation is made for the use of "green" methods to save energy and to increase the productivity and quality of work performance. Companies including Boeing, Wal-Mart, Sealtest, Hyde Tools, AT\&T, and DOW Chemicals are used to illustrate how the change to a "greener company" can add to the increased productivity of the office as well. "Lean and dean" is more than a management philosophy. Romm claims it is a behavior that everyone needs to master in order to survive and succeed in the next decade. This centers on the idea of reducing non-labor costs, and will ultimately help preserve wages, jobs, and a competitive edge in the future.

Romm, J oseph J ., and William D. Browning, "Greening the Building and the Bottom Line: Increasing Productivity Through Energy-Efficient Design" (Rocky Mountain Institute, December 1994).

Abstract: This paper describes case studies of companies that decided to increase the energy efficiency of their buildings, and thereby inadvertently increased worker productivity. In the eight cases profiled, efficient lighting, heating, and cooling measurably increased worker productivity, decreased absenteeism, and/or improved work quality. These cases show that productivity gains from energy-efficient design can be as high as 16 percent, providing additional savings in excess of the energy savings alone. They also show that efficient lighting in particular can measurably increase work quality by reducing errors and manufacturing defects.

Rubin, Arthur I., and Belinda L. Collins, "Interim Survey of Selected Military Building Environments: A Research Approach," National Bureau of Standards, Gaithersburg, MD, NBSIR 87-3606 (August 1987). 
Abstract: Because many military and civilian employees of the U.S. Army are required to work in environments unlike those experienced by most civilian workers, a project involving a comprehensive assessment of such workplaces was initiated. This assessment involved a two-phase effort in which the first phase consisted of a literature search, interviews with experts, site visits, and limited field environmental measurements. The second phase will include a comprehensive assessment of environmental conditions, including lighting, at selected military facilities. The report documents findings from Phase 1 , including a detailed bibliography of target areas: lighting, stress, and shift work. It also includes preliminary results from a visit to two military field stations. During each visit, selected individuals including supervisory, operational, analytical, and maintenance personnel, were interviewed to determine their opinions of the environmental conditions. At the same time, limited field measurements were made, including lighting, noise, temperature, humidity, and particle counts (at Site 2 only). Preliminary data and recommendations are presented.

Rubin, Arthur I., and Belinda L. Collins, "Evaluation of the Working Environment at Selected U.S. Army Field Stations: Suggestions for Improvement," National Bureau of Standards, Gaithersburg, MD, NBSIR 88-3827 (August 1988).

Abstract: A detailed evaluation of environmental conditions in U.S. Army field stations was undertaken in response to concerns expressed by Headquarters, U.S. Army Intelligence and Security Command. This report presents findings and recommendations based on interviews with station personnel, questionnaire responses from more than 600 building occupants, extensive measurements of physical conditions, and careful observation of a host of representative activities. In 1987 three field stations were evaluated: Kunia, Hawaii; Augsburg, Germany; and Berlin, Germany. The findings confirmed the concerns expressed by headquarters-field station personnel perform their jobs under conditions likely to impair their effectiveness. These include poor thermal, lighting, and acoustic conditions; furnishings such as chairs and desks in poor repair; dysfunctional equipment; and general lack of regular maintenance in the facilities. Suggestions for improving facility conditions are presented. Data collected during the field portion of this study were presented in an earlier report by Collins and Rubin.

Siero, Frans W., Arnold B. Bakker, et al., "Changing Organizational Energy Consumption through Comparative Feedback,"J ournal of Environmental Psychol ogy, vol 16, 235-246 (1996).

Abstract: Two units of metallurgical companies in the Netherlands were examined to understand the differential effects of two forms of feedback. In the first unit, they received information about energy conservation, had goals for their unit, and also received performance information for their unit. The second 
group received all the information that the first had, but were also given information about the first group's performance. In results predicted through social identity theory and social comparison theory, the second group performed better, or saved more energy than the first. This study does not address the issue of negative comparison effects. In this study, the second group performed higher than the first, and the comparison to the first group helped them. However, if the second group had continually performed worse than the first group, it could have had an adverse effect and dampened productivity. This study did show findings that demonstrated a change in behavior with little change in attitude.

Sullivan, Edward, "Does Office Design Hinder Employee Productivity?," Building Operations Management, pp 18-21 (August 1995).

Abstract: The design of any space influences the actions that result from that space. Sullivan looks into the design of corporate offices to assess whether their layouts or "templates" have an affect on both worker productivity and office atmosphere. Opening up offices to increase worker communication has become the practice. A key to effective team-based spaces is large open floor plates. However, larger floor plates are not always practical since the resale of a building is also important, and limited floor plates allow a building to be divided more easily into multiple tenants later. Another trend is to get the employee closer to the customer. This has led to alternative office set-ups such as office sharing, telecommuting, and car offices. Flexibility of office space is important to efficient moving and keeping costs manageable. Better employee communication is solved by establishing "waterholes" that are shared office areas housing common uses such as copiers, fax machines, and coffee stations. This plan allows the members of a team to find time to communicate in a comfortable and useful space. Communication and employee efficiency seem to be directly related to the office layout and, therefore, have warranted further investigation into cause and effects.

Sullivan, Edward, "Elements of a Productive Indoor Environment," Building Operating Management, pp 22-27 (1995).

Abstract: The design focus of today's offices is not storage or carpeting unless it pertains to the overall design question, "How do we design the space so performance is better?" This article reviews the main issues of performance 
design today and briefly details some of the major ideas on the subject. The topics of lighting, thermal control, noise, and accessibility are covered.

Veitch, J ennifer A., and Robert Gifford, "Choice, Perceived Control, and Performance Decrements in the Physical Environment,"J ournal of Environmental Psychol ogy, vol 16, pp 269-276 (1996).

Abstract: Providing choices in a physical environment has been asserted to increase performance, better moods, and improve conditions for employees. This theory was tested in an experiment using a $2 \times 2$ Choice (over lighting) $\mathrm{x}$ Preference (for lighting) factorial design and also an additional no-treatment group. The 2-hour study included male and female undergraduates who performed various creative and intellectual tasks. As expected, the group given the choice reported more perceived control than the group in which preference was denied. However, the preference-denied condition group performed faster and better in the creativity tasks.

Woods, J ames E., "Cost Avoi dance and Productivity in Owning and Operating Buildings.

Occupational Medicine," State of theArt Reviews, vol 4, pp 753-769 (1989).

Abstract: This paper explores the economic impacts of unacceptable environmental control in buildings. It suggests that 20 percent of office workers in the United States may be exposed to environmental conditions that are manifested as symptoms associated with sick building syndrome (SBS). The predominant types of stressors are chemical and particulate contaminants, thermal discomfort, microbiological contaminants, and non-thermal humidity problems. The costs that should be considered are the occupant's salary, medical care, and health insurance; and the owner/operators' rent, utilities, O\&M, capital assets, construction, and salaries. A Productivity I mpact F actor can be calculated as the ratio of savings in energy cost compared with the cost at risk (e.g., salaries). As a result, the lost work time would nullify the energy savings if the energy saving procedures adversely affected the indoor environmental quality. The national economic losses due to poor indoor environmental quality can be tens of billions of dollars per year. If investments in improved design, construction, and maintenance of buildings results in slightly decreased absenteeism or increased productive concentration, the investments may be highly cost-effective. The discussion concludes with some recommendations to achieve savings in owning and operating buildings without compromising the health and comfort of the occupants. Also included are some suggestions on how to use these procedures to improve productivity.

Wyan, D., "Predicting the Effects of Individual Control on Productivity,"J Cl Research Fellow (1996). 
Abstract: This report attempts to predict the effect that individual control of changes of $\mathrm{H}-3{ }^{\circ} \mathrm{C}$ of the workstation cooling and heating may have on productivity. One theory is that this margin of control would enable 99 percent of the workers to reach thermal comfort if the ambient temperatures were set to the group optimum. Giving the workers this control increased productivity by 2.7 percent, while the improvement rose to 15 percent if the range of control was $H-5{ }^{\circ} \mathrm{C}$. The overall effect each person experienced was related to how long the individual spent at different types of tasks.

Young, H.H., and Gayle L. Berry, "The Impact of Environment on the Productivity Attitudes of I ntellectually Challenged Office Workers," Human Factors, vol 21, no. 4 (1979).

Abstract: This paper describes research conducted to evaluate the impact of lighting, noise, pleasant sounds, and landscape on the productivity of eleven office workers involved in decisionmaking, design, and creative work. An experimental office was created with one real and one artificial window, and a large back-lit screen where movies of several nature scenes were shown. Speakers were placed on each side of the artificial window for introducing nature sounds, industrial noise, and large office noise. Eleven regular staff members of Arizona State University were vol unteer subjects, performing their normal tasks in the experimental office, and occupying the office in groups of two and three. Thirteen environmental conditions were established with varying combinations of no noise, large office noise, industrial noise, music, nature sounds, outside window, artificial window, and no window. Each day was divided into two experimental periods, morning and afternoon, with environmental conditions randomly assigned. An evaluation form was completed by each participant at the end of each day regarding subjective reactions of comfort and accomplishment, comparison of the day's two exposures on preference and productivity, subjective evaluation of lighting, blocking effect of music or nature sounds on industrial or office noise, comparison of each exposure to the baseline condition (real window, no noise), best and worst environmental condition to date, and comparisons of the experimental conditions to the subject's regular office facility. All participants preferred a window, whether it was the real window or the artificial window with movies projected. The preferred conditions also included complementing sounds of either music or nature sounds. The researchers concluded that music and nature sounds are equally attractive as sound complements, an artificial window with nature movies projected is a viable substitute for an outside window in an interior office, and complementing sounds reduce the unpleasant effects of cyclic noises but may amplify the unpleasant effects of random, semi-continuous noises. The researchers suggest further research where objective measure of productivity is used in place of subjective 
reports of individuals. It would also be valuable to validate this study's findings in an organizational setting.

\section{Lighting}

Audin, Lindsay, David J . Houghton, et al. State of theArt: Lighting (Competitek, 1997).

Abstract: This volume is an all-inclusive resource for making lighting design and retrofit decisions. It discusses the systems approach and why it is critical to capturing lighting savings. The interaction of human behavior, productivity, and visual comfort with lighting systems are discussed. Current lighting stock is described as well as more efficient alternatives, in both theory and practice. It contains a set of tools useful for lighting designers, building managers, and specifiers including a review of lighting software, lighting loggers and occupancy sensors, a summary of the lighting provisions of ASHRAE 90.1, and a sample lighting specification.

Bernecker, Craig A., and George Brainard, "The Physiological and Psychological Effects of Lighting," Lightfair International (1994).

Abstract: Experimental studies have demonstrated that light can influence human physiology, mood, and behavior. Laboratory results can now be incorporated into practical architectural lighting designs which optimize illumination for biological stimulation as well as follow traditional guidelines for providing correct visual stimulation and comfort. This novel consideration for lighting design may dramatically alter future illumination strategies for homes, offices, factories, hospitals, schools, and other buildings.

Collins, Belinda L., "Evaluation of the Role of Luminance Distributions in Occupant Response to Lighting," CIBSE National Lighting Conference (1994).

Abstract: This paper presents findings from a detailed analysis of POE data, which involved 912 work stations in thirteen office buildings typical of current lighting design practice. Occupants were queried regarding brightness, amount of light available, and overall satisfaction with lighting. Task illumination and average workspace luminance was measured or calculated. Analysis of the data indicated that occupant satisfaction could be related to patterns of luminance, lighting characteristics, and presence of daylight in the office. The combination of a bright task surface with dim surroundings produced an unappealing lighting situation, despite adequate task illuminance. The indirect ambient lighting located in the top of the furniture system and directed up to the ceiling often resulted in a very non-uniform pattern of ceiling luminance with many dark 
areas. The fixed task lighting caused specular reflections on the task, reducing task contrast and visibility. Occupants had no control over the position or direction of the task light. An analysis of the distribution of lighting satisfaction ratings indicated that people with daylight were significantly more satisfied than those without. Results suggest further research is needed to evaluate means of increasing the effectiveness of task lighting. Future POE analyses should include more detailed photometric characterization of the space involved.

Collins, Belinda L. et al. "Evaluating Office Lighting Environments: Second Level Analysis,"

National Institute of Standards and Technology, NISTIR 89-4069 (April 1989).

Abstract: Data from a POE of 912 workstations with lighting power density (LPD), photometric, and occupant response measures were examined in a detailed, second-level analysis. Seven types of lighting systems were identified with different combinations of direct and indirect ambient lighting, task lighting, and daylight. The mean illuminance, with body shadow at the primary task location, were within the Illuminating Engineering Society of North America's (IESNA) target values for office tasks with a range of mean illuminances from 32 to 75 FC, depending on the lighting system. The median LPD was about 2.36 W/sq ft, with about one-third of the workstations having LPD's at or below 2.0 $\mathrm{W} / \mathrm{sq} \mathrm{ft}$. Although a majority of the occupants (69 percent) were satisfied with their lighting, the highest percentage of those expressing dissatisfaction (37 percent) with lighting had an indirect fluorescent furniture mounted (IFFM) system. The negative reaction of so many people to the IFFM system suggests that the combination of task lighting with an indirect ambient lighting system had an important influence on lighting satisfaction, even though task illuminances tended to be higher with the IFFM system. Concepts of lighting quality, visual health, and control were explored, as well as average luminance to explain the negative reactions to the combination of indirect lighting with furniture mounted lighting.

Eklund, Neil, and Peter Boyce, "The Development of a Reliable, Valid, and Simple Office Lighting Survey," Rensselaer Polytechnic Institute (March 1995).

Abstract: This is a report of a survey method that provides a questionnaire along with found data to help deliver effective lighting surveys. Only two surveys with extensive normative data exist, Vischer's Lighting Comfort Scale (LCS) (1989) and Gillette and Brown's Occupant Questionnaire (OQ) (1986). The LCS has limited diagnostic ability, is difficult to score, and was developed to determine overall office quality. The OQ was developed to quantify "good office lighting" and is somewhat more diagnostic than the LCS but more labor intensive to score. The Office Lighting Survey (OLS) was designed to be simple 
and rapid to score, and provide considerable diagnostic information when problems were found.

Gillette, Gary, “Evaluating Office Lighting Environments: Reference Lighting Power Density Data," National Bureau of Standards, NBSIR 88-3691 (J anuary 1988).

Abstract: This document reports on an exercise in archiving in situ lighting power densities for occupied office lighting environments. Using data from a previous study where field surveys of existing lighting installations were recorded, the present study extends these data to indude referenceable lighting power densities for the installed conditions. In addition, theoretical alternate American National Standards Institute (ANSI) lighting power densities were computed assuming one-for-one replacement with either energy saving or standard lamps and ballast.

Illuminating Engineering Society of North America, Lighting Handbook: Reference and Application, (IESNA, 1993).

Abstract: This is a comprehesive handbook that discusses the important and complementary aspects and principles of lighting. In general, it defines the basic principles such as luminaire, efficiency, luminous efficacy, Ohm's law, electricity, current, etc. This text gives a good background on lighting principles and definitions.

Katzev, Richard, "The I mpact of Energy-Efficient Office Lighting Strategies on Employee Satisfaction and Productivity," Environment and Behavior, vol 6, 759-778 (1992).

Abstract: This paper describes a project designed to investigate the productivity, preferences, and affective impact of energy-efficient office lighting systems. Twenty-four office employees were rotated in a counterbalanced order through three such systems and one standard control system, spending approximately an hour and a half in each. The subjects "worked" on five computer-presented performance tasks, responded to a questionnaire about their current mood, and evaluated the lighting system in each officelab. There were significant differences between the lighting systems in terms of employee satisfaction. However, with the exception of a reading comprehension test, they had a relatively modest effect on the subjects' performance on other cognitive/ intellectual tasks. The findings indicated that initial reactions to the lighting systems tended to dissipate over time, so that with continued exposure, the subjects adapted to the new lighting conditions and displayed few changes in their performance or mood. The findings indicate that it is possible to introduce more energy-efficient lighting systems to contemporary office environments that will be both appealing to office employees and maintain the overall quality and 
accuracy of their performance. Future research would benefit by investigating the effects of lighting conditions on a greater range of mood states than performed in this study. In addition, an effort should be made to identify possible associations between mood states and performance, as well as mechanisms that might mediate this relationship.

Lamarre, Leslie, “Lighting the Office Environment," EPRI J ournal (May/J une 1995).

Abstract: Now that VDTs are as common as telephones in an office or work environment, to properly light these spaces has become a critical task. Overillumination, a common problem, can create a glare on the VDTs and create too much contrast between the terminals and the surrounding areas. Such effects have the problems of creating difficult work environments and making workers feel uncomfortable, with problems such as eyestrain, headaches, weariness, and other obstacles affecting the ability to perform. The Electric Power Research Institute (EPRI) has collaborated with Lightolier to develop a new line of luminaires and controls that are specifically made with VDTs in mind.

Lighting Professionals, Inc., A Lighting Reference Manual, (Montvale, NJ ) n.d.

Abstract: This series of charts and diagrams contains recommendations on lighting design. It includes some basic lamp technology and levels of illumination ranges. General advice is provided for type and placement of recessed fixtures, lighting specular surfaces, lighting 3-dimensional art, and lighting vanity mirrors. Several examples are shown.

Mahdavi, A., P. Mathew, Kumar, V. Hartkopf, and V. Loftness, "Effects of Lighting, Zoning, and Control Strategies on Energy Use in Commercial Buildings,"J ournal of thellluminating Engineering Society (Winter 1995).

Abstract: This paper presents simulated studies that are part of a larger research effort to assess the implications of end-use technologies and DSM on occupant satisfaction. There is special consideration given to increased zoning and individual controls. Additional data to support literature is provided along with a preliminary assessment of the energy-related implications of thermal zoning strategies with regards to lighting system operations, enclosure configurations, and control strategies in commercial buildings. As far as studies of lighting load reduction, interest was taken into (a) application of more effective lighting sources, (b) selection of split task-ambient systems and other flexible system configurations, (c) design of more resolved zoning to account for variable-occupancy and personal control, and (d) use of daylight and dimming technology. 
Mesh, Steven, “Quantifying Lighting Quality,” Building Operation Management, pp 32-40 (1995).

Abstract: This is a goal-oriented article. It describes lighting in terms of footcandles and other measures of luminance and illuminance. It describes good lighting as lighting that is not paid attention to and implies if you notice the light conditions, it is most likely poor lighting. The article shows step-by-step how to achieve proper lighting and gives appropriate horizontal illuminance ratings for spaces.

National Electrical Manufacturers Association and the Lighting Research Institute, "Lighting and Human Performance: A Review," Washington, DC (1989).

Abstract: This study provides scientific evidence of lighting's ability to affect how people work, how it can influence attention spans and mental fatigue, and how it can have profound physiological and psychological impacts. It is a compilation of research including authenticated case studies and thoroughly documented laboratory experiments. This study recommends further work in quantifying the effects of lighting on workers to enhance design capabilities.

National Lighting Bureau, "Office Lighting and Productivity," Property Management Association (1988).

Abstract: Office tasks have evolved over the years from desk and paper to VDTs. Lighting cutbacks in the 1970s reduced office productivity by as much as 25 percent. The cost of a 10 percent loss in productivity is $\$ 11.50 / \mathrm{sq} \mathrm{ft} / \mathrm{year}$ compared to a lighting cost of $\$ 0.25 / \mathrm{sq}$ ft/year for the typical office building. New office lighting techniques are not easy to master and, if not used properly, their application can prove counter-productive.

Puleo, S., B. Hartleb, and R. P. Leslie, "Some Effects of the Sequential Experience of Windows on Human Response,"J ournal of the Illuminating Enginering Society, vol 20, no. 1 (1991).

Abstract: This paper describes a research initiative to examine the impact of windows on productivity, mood, decisionmaking, and willingness to stay at a work task. Sixty graduate students were given a performance test, decision making test, mood evaluation questionnaire, and final questionnaire rating the room, importance and suspected influence of a window, and what would be a fair rate of pay to work on the tasks in that room. Two rooms were used, identical in all respects except for the presence of a window. Subjects were randomly assigned to one of four test conditions, W to W, W to NW, NW to W, NW to NW, with 15 subjects per condition. While the pilot study indicated that most people have a preference for windows and believe windows improve task performance, the results of this experiment did not demonstrate improved performance. 
Practice at the performance test had a much larger effect than windows. Furthermore, the data implied that windows detracted from performance in the beginning of a work session and for short-term tasks (25 minutes in this experiment). It may be this observed negative impact of windows is not sustained over time because more variables come into play. Therefore, conclusions drawn about windows' effect on short-term tasks may not be applicable to long-term tasks. In response to three Discussions/Reviews, the authors conclude that windows have a detrimental effect on short-term anagram-like tasks, but may have a positive effect on performance over longer time periods. This study should be carried to yet longer time periods to simulate the effects of windows on human response over the course of a work day.

Rea, Mark, Peter Boyce, and Naomi Miller, "Light Conversations," Rensselaer Polytechnic Institute, Troy, NY (1994).

Abstract: This is a bulletin written as a dialogue between four parties. Their conversation takes the reader through an overview of lighting design. The focus is on its importance, costs, environment, etc. Photographs, charts, and graphs illustrate the text in order to provide a more visual representation of some of the ideas.

Ryan, B.J ., "Lighting Design Strategies For Energy Optimization and Human Performance", Energy and Environmental Strategies for the 1990s, Proceedings of the $13^{\text {th }}$ World Energy Engineering Congress, October, 1990, (Association of Energy Engineers, Atlanta, GA, 1990).

Abstract: The lighting design evolution has taken place in an era of dynamic technological developments and an awareness of the value of our working environment. The advent of a national concern for energy efficiency was one milestone in this evolution. Most recently, the appearance of psychological and behavioral concerns for building occupants has emerged. These concerns required lighting designers to integrate less quantifiable measures into the traditional mathematical design models. This discussion looked at the philosophies guiding lighting design strategies and focused attention on the importance of customized design solutions for visual environments in the workplace. 
Abstract: This is a report of a study involving numerous bottling plants and the work by their inspectors. Visual inspection of the bottles from plants was looked at with regard to the variables influencing this work. Items such as speed of the production line, visibility, glare, reflection, contrast, and other variables were observed. The results revealed that there appeared to be optimum conditions existing relevant to each factor influencing work speed, work spell, and other work-related functions.

Sanders, Philip A., and Belinda L. Collins, "Post-Occupancy Evaluation of the Forrestal Building,"

National Institute of Standards and Technology, Gaithersburg, MD, NISTIR 5591 (March 1995).

Abstract: This paper summarizes the results of a POE conducted at the DoE's Forrestall Building in Washington, DC. As part of the Federal Re-lighting Initiative, and in order to reduce electricity consumption, the DoE headquarters was relighted during the summer of 1993 . Physical lighting characteristics were measured both before and after the retrofit. An occupant questionnaire was administered at the same time the physical data was collected. The data indicated the re-lighting effort improved lighting conditions. Results of the occupant questionnaire indicated the retrofit improved attitudes toward the lighting for a significant number of building occupants. This paper provides recommendations for conducting a POE including determining sample size and composition, suggested questionnaire contents, suggested physical measurements, and collecting and analyzing the data. Appendices include the questionnaire used in this study and the suggested physical measurement form for the reader who wishes to conduct a POE.

Tatum, Rita, “N ew Age of Lighting Retrofit,” Buil ding Operating Management, pp $44-47$ (1995).

Abstract: The modern trend in lighting asks whether a savings in cost for lighting is more expensive if worker satisfaction and productivity go down. Lighting systems have become very inexpensive in energy consumption, but not all produce enough or the proper type of lighting to motivate or keep work spirits high. By designing lighting schemes that help the employee, more money is saved. This article also discusses the issues of veiling and direct/indirect light. 
Abstract: Energy-efficient lighting is becoming code around the world. One fear is that as the power supplied to area lighting drops, so will the quality of the lit environment. A problem surrounding this argument is the lack of governing metric of lighting quality. A commonly accepted belief is that poor lighting negatively impacts human performance. This paper attempts to offer a definition of lighting quality in terms of the success or failure of a design based on the needs of the end-users.

\section{Thermal Control}

American Society of Heating, Refrigerating and Air Conditioning Engineers, "Standard 55-1992:

Thermal Environmental Conditions for Human Occupancy," ASHRAE, Atlanta, GA (1992).

Abstract: This standard specifies the combinations of indoor environment and personal factors that produce thermal environmental conditions acceptable to at least 80 percent of the occupants. The environmental factors addressed are temperature, thermal radiation, humidity, and air speed. The personal factors addressed are level of activity and clothing.

American Society of Heating, Refrigerating and Air Conditioning Engineers, "Chapter Eight:

Physiological Principles and Thermal Comfort," ASHRAE Fundamentals Handbook (1993).

Abstract: This handbook specifies the workings of the thermal functions and responses of the human body. It describes the body's response to thermal change and gives formulas to predict body temperature change and its effect based on environment. It assists in finding numbers for values such as skin heat loss and the moisture permeability of some dothing.

Hedge, Alan, Abigail T. Michael, and Sharon L. Parmelee, "Reactions of Office Workers and Facilities Managers to Underfloor Task Ventilation in Offices,"J ournal of Architectural \& Planning Research, vol 10, no. 3 (1993).

Abstract: This paper is an evaluation of the reactions of 6 facilities managers and 151 office workers to underfloor task ventilation as reported in two selfreport questionnaire surveys. The underfloor task ventilation modules allow individual control of fan velocity and direction of airflow, and were easily relocated. Facilities managers reported fewer complaints about thermal and ventilation problems than with the previous overhead HVAC systems. Four of the six managers said that they would definitely use a task ventilation system again if they were renovating or constructing another building and the other two managers said that they would probably choose a task ventilation system again. Office workers also reported high levels of satisfaction with the task ventilation 
system. Two-thirds of workers said that the underfloor task ventilation system provided better temperature and ventilation conditions compared with the overhead ventilation system. A majority of workers also said that these conditions better supported their productivity and helped to maintain alertness at work. Since the surveys were given after occupation of the new buildings, information given on the old building's HVAC systems was subject to recall bias. The opinion surveys could not be compared with the ambient conditions in the office and whether or not the old building's HVAC systems were operating correctly, or its environmental conditions. Future research should include both pre and post-move surveys and should measure ambient conditions of both buildings.

Houghton, David J ., and Robert C. Bishop, State of the Art: Space Cooling and Air Handling (Competitek, 1992).

Abstract: This volume addresses the energy saving potential of space-cooling and air-handling systems and the means to achieve it. The discussion on institutional reforms recommends reform of the design fee structure, use of integrated packaging of measures for optimal sizing, greater cooperation among disciplines, and risk sharing and flexibility to encourage the use of new technologies. The discussion on technical opportunities indudes controlling unwanted heat gain, applying non-vapor compression cooling techniques, improved controls, and proper building commissioning, maintenance, and training of operators. The discussion on economics addresses the use of life-cycle costing as a decisionmaking tool during the planning stages of construction. The discussion on utility opportunities describes suggested changes to utilities' demand side management programs to tap the large savings available in spacecooling and air-handling.

Lovins, Amory B., Air Conditioning Comfort: Behavioral and Cultural Issues (E Source, Inc., 1992).

Abstract: A better understanding of what determines individual perceptions of thermal comfort under hot and/or humid conditions could lead to changes in the design and use of air conditioning, reducing peak loads and saving money. The savings could be significant since an increase of $1{ }^{\circ} \mathrm{C}$ in design room temperatures in a large commercial building typically reduces cooling energy by several percentage points. Conventional "comfort engineering" has overlooked factors such as acdimatization, dependence, and physiological variations among individuals. When choosing comfort conditions in everyday life, people show a far wider range of preferences than they do in laboratory experiments. Studies of how people operate their air conditioners suggest opportunities for better control systems that could improve comfort and save energy. Task conditioning 
may improve comfort and productivity - office workers stay healthier and perform better given more control over their workplace environment.

York, Theodore R., "Conquering the Last Ergonomic Barrier: Temperature Control," FM J ournal, 7-14 (1994).

Abstract: This article reports that the greatest complaint from employees working in a multitude of environments is unsatisfactory temperature comfort. Individuals have different metabolisms, dress differently, and have different heat generating equipment in their work areas. Building HVAC systems are designed with one workspace configuration in mind while the average annual churn rate (rate of employee workspace moves) is approximately 41 percent. The proposed solution is to let employees have control over the temperature in their immediate work areas through the use of access floor, a modular electrical distribution system, and under-floor air. The installed cost of this system is less than 1 percent greater than traditional ceiling air distribution systems. Operating expenses are low and temperature comfort is gained along with flexibility for change.

\section{Indoor Air Quality}

American Society of Heating, Refrigerating and Air-conditioning Engineers, "Standard 62-1989:

Ventilation for Acceptable Indoor Air Quality," ASHRAE, Atlanta, GA (1989).

Abstract: This standard specifies ventilation rates and IAQ that will be acceptable to human occupants and is intended to minimize the potential for adverse health effects. It also applies to occupied indoor spaces, except where stricter standards exist.

Boschi, N., P. Carrer, C. Domenico, C. Schlitt, and M. Maroni, "Indoor Air Quality Evaluation of an Ancient Multistoried Office Building in Downtown Milan, Italy (Phase I \& II)" Unpublished report, n.d.

Abstract: As more reports of dissatisfaction with building environments occur, a better knowledge of the nature of indoor environments becomes necessary. This is a study of a building in downtown Milan, I taly, now being used for office space. This was a phased study. The first phase was a walk-through, gathering basic building information. Phase two included evaluation and collecting data on the IAQ and other environmental concerns.

Brundage, J .F., R.M. Scott, W.M. Lednar, et al., "Building-Associated Risk of FebrileAcute Respiratory Diseases in Army Trainees,"J ournal of theAmerican Medical Association, vol 259 (1988). 
Abstract: This paper stated that airborne transmission of infectious agents and associations of indoor air pollutants with respiratory illnesses is well documented. The authors hypothesize that energy conservation measures that tighten buildings also increase risks of respiratory infection among building occupants. At four Army training centers during a 47-month period, incidence rates of febrile Acute Respiratory Disease (ARD) were compared between basic trainees in modern (5 percent outside air, three air changes/hour) and old barracks (40 percent outside air). Rates of ARD were significantly higher among trainees in modern barracks, and relative risks were consistent at the four centers. Two periods of epidemic ARD occurred prior to institution of year-round adenovirus immunizations. Several findings suggest that modern barracks increased ARD risk by aiding the transmission of respiratory pathogens among immunologically susceptible trainees. In contrast, rate differences between old and modern barracks were negligible during periods of low overall ARD incidence, after institution of year-round adenovirus immunizations, and during the early weeks of training. It is possible that the risk attributed to modern barracks in this study was modified by, or entirely related to, one or more unmeasured confounding factors. Studies are necessary to define and quantify the risk factors of building-associated respiratory tract infection, develop costeffective methods of decreasing their transmission, and estimate medical and non-medical expenses attributable to building design characteristics.

Caldwell, Barnett, "I ssues in Environmental Quality Affected by Ventilation Systems," U niversity of Wisconsin-Madison (1994).

Abstract: This reference was a discussion of the increasing awareness of environmental factors affecting human performance. By addressing such issues as ventilation, temperature, and toxins, it explores how human action in an office, an educational institution, and a school, is affected by environmental pollutants. The article examines how these pollutants, whether noise, smell, or other factors can have direct physiological effects as well as indirect psychological and socio-cultural effects. These influences are then analyzed to show how ventilation effects environmental quality.

Chamberlin, Glen A., Darren B. Myers, J ames M. J ones, Peter Rojeski J r., and Harmohindar Singh, "Carbon Dioxide and Ventilation Rates," TR-95/08, U.S. Army CERL, Champaign, IL (J une 1995).

Abstract: This report discussed the history of ventilation standards for the purpose of reducing $\mathrm{CO}_{2}$ and controlling odor and known toxins. At present it is felt that high $\mathrm{CO}_{2}$ levels in building interiors may be an indicator that other indoor pollutants are present in dangerous amounts. A section is devoted to a description of historical ventilation standards from King Charles I to ASHRAE 
62-1989. Another section describes gas sensing technologies. Instructions are given for calculating outdoor air flowrate requirements. The author concluded with a recommendation for further evaluation of $\mathrm{CO}_{2}$ sensors to control outside air ventilation rates for accuracy and reliability.

Moschandreas, D. J ., J . Woods, M. Maroni, and N. Boschi, "Evolving Educational Paradigms for Health and Building Professionals" n.d.

Abstract: This paper is intended to document and discuss the problems involved with integrating health and building science. This problem has arisen due to a difference in methods, technical language, and cultural references between the two groups. While realized to be an important integration, it has proven difficult to attain. The text is divided into two parts. The first documents shortcomings that typify the present educational practices in graduate and post-graduate programs for health and building related professions. The second is a description of major international programs for filling the gaps in IAQ education.

Helsing, Knud J ., "Cure of a Sick Building: A Case Study," Environment International, vol 15, 107114 (1989).

Abstract: This paper describes a sick building investigation from the commissioning of a new junior high school to the resolution of complaints from teachers and students. After several years of complaining of SBS symptoms, the Board of Education requested help from J ohns Hopkins School of Hygiene and Public Health. They conducted an investigation that consisted of a survey of absenteeism and student performance records; physical examinations of faculty and staff; air monitoring for $\mathrm{SO}_{2}, \mathrm{CO}$, and $\mathrm{CO}_{2}$; a smoke test of the sewer system; an investigation of cleaning materials; airflow tests; and a general inspection of ventilation intakes and exhausts. In addition, parents of eighth graders at the affected school, as well as two other schools, were given a questionnaire regarding their child's health. Though the reported symptoms from students at the affected school were double those of the other schools, levels of $\mathrm{SO}_{2}, \mathrm{CO}$, and $\mathrm{CO}_{2}$ were within allowable limits. Total airflow, however, was well below the ASHRAE recommendation. Several ventilation intakes were located in areas of stagnant air or close to ventilation or school bus exhaust fumes. Three openings were found in sewer lines. Once corrective measures were taken, the survey of eighth graders' parents was again conducted. The incidence of reported SBS symptoms at the affected school was half that of the first survey, and comparable to those of the other schools surveyed. The author concluded that a lack of response to complaints of SBS may have caused an increase in symptoms due to frustration and anger with the situation. Many records are available (such as attendance and sick call) to check against reported symptoms. It is suggested that investigators look for the obvious sources of contaminants first. It is also 
suggested that controllable thermostats would increase the level of satisfaction among occupants.

Hodgson, M., and E. Storey, "Susceptibility and Specific Syndromes: Patients and the Sick Building Syndrome," Occupational and Environmental Medicine, Department of Medicine, University of Connecticut (1994).

Abstract: More frequently, physicians are faced with complaints based on indoor environmental problems. Physicians must distinguish between the identification of disease in individual patients, characterization of group effects, and analysis of environmental exposure characteristics. Problem solving for the high frequency of indoor environment related sickness calls for the joint efforts of engineers, industrial hygienists, and others.

Holcomb, Larry C., and J œ F. Pedelty, "Comparison of Employee Upper Respiratory Absenteeism Costs with Costs Associated with Improved Ventilation," ASHRAE Transactions: Symposia, OR-94-13-3, 914-921 (1994).

Abstract: Indoor air has often proven to possess a higher number of pollutants than outdoor air. This, combined with the fact that most Americans spend more than 90 percent of their day indoors, shows how adults' major source of airborne pollutants comes from indoor air. This air is believed to be the cause of an increased incidence in upper respiratory symptoms that can lead to absenteeism and a drop in company or worker productivity. However, very little has been done to quantify or correct this problem. Current data can be used to estimate the productivity lost, as well as the cost of correcting poor or inadequate air quality in existing and future buildings.

J aakkola, J .J .K., and O.P. Heinonen, "Sick Building Syndrome, Sensation of Dryness and Thermal Comfort in Relation to Room Temperature in an Office Building: Need for Individual Control of Temperature," Environment International, vol 15 (1989).

Abstract: This paper documents a study of a modern eight-floor office building in Helsinki, Finland, with 2150 office workers and their perceptions of SBS symptoms, dryness, and thermal comfort. All spaces have mechanical ventilation but this study concentrated on the majority of the building without air conditioning and humidification. The hot water radiators are controlled in blocks so individual room temperature control is not possible. Measurements were made of airflow, temperature, relative humidity, air velocities, exposure concentrations of chemical and biological factors, partides, ions, and radon. The overall trend was low relative humidity, great variation in room temperature, high average temperature, and low concentration of measured indoor air pollutants. Each worker filled out a questionnaire about symptoms, previous and present disease, complaints, health behavior, attitudes toward working 
conditions, and details of home and working environments. Room temperature was the strongest predictor of SBS symptoms and sensation of dryness. There was a direct relationship between SBS symptoms and increase in room temperature above $22{ }^{\circ} \mathrm{C}$. There was also a high incidence of SBS symptoms when room temperature was rated as too low. This study concluded that SBS symptoms were an expression of dissatisfaction with temperature. It suggested that individual control of room temperature would decrease reported SBS symptoms in office workers.

McCarthy, Sharon M., "Overview of Sick Building Investigations and Legal Issues," Energy

Engineering: J ournal of the Association of Energy Engineers, vol 90, no. 6 (1993).

Abstract: This paper defines SBS and Multiple Chemical Sensitivity (MCS) and discusses the reasons for increases in both, along with the interactions that may influence perceptions of SBS and MCS. The author describes indoor air pollutants and provides the sources for each one. A description of an indoor air investigation follows. Five cases of SBS, that are in or have been through litigation, are reviewed with highlights of the legal issues addressed. The author provides guidelines on how to avoid SBS litigation. In conclusion, a proactive stance is recommended, either through proper design and commissioning of HVAC systems or in prompt attention to SBS allegations from building occupants.

Pierce, Stanley, and J oseph J . Ortego, "E merging Trends in U.S. Indoor Air Pollution Litigation,"

Toxicological And Environmental Chemistry, Vol 40 (1993).

Abstract: This paper provides a general description of the various toxins and symptoms associated with SBS, highlighting the increase in reported SBS since the emphasis on energy efficiency brought about by the energy crisis of the 1970s. The author reports that the ultimate cost of SBS could exceed tens of billions of dollars, and account for fully half of all employee absenteeism. The trends and theories in liability for manufacturers, architects, builders, landlords, tenants, and others are discussed with several examples of actual court cases. The loss by the plaintiffs in most of the cases was due to the lack of acceptance by the medical community of environmental chemical sensitivity syndrome, and because of insufficient proof of the cause and effect relationship of the alleged toxins. The most effective way to minimize liability for poor IAQ is to avoid toxic building materials and provide adequate ventilation, though both options increase building and operating costs. Planning and intelligent construction may be an asset from both a worker productivity and a liability standpoint. The author concludes that although the courts have yet to find that a non-massproduced building is subject to liability laws as a product, the potential financial rewards for successful litigants show why the plethora of IAQ cases continue. 
Sensharma, N., P. Edwards, J . Woods, and J . Seelen, "A Characterization of Methodologies for Assessing Human Responses to the Indoor Environment," Proceedings of 1993 Indoor Air Quality Conference, vol 1 (1993).

Abstract: Indoor environmental studies have produced many divergent results. Some reasons for these differences are addressed in this paper. Several extraneous reasons and methodological effects account for some of this divergence. Human responses are classified into four domains and each domain has extraneous characteristics assigned or associated to it. The reporting methods are classed into three methodologies with their effects. A process of pairing human responses with the governing extraneous factors is supposed to lower the amount of false-positive or false-negative in sick building or healthy building analysis.

White, W. Curtis, and Christine C. Brillhart, "On-siteAssessment of Microorganisms and Volatile Organic Compounds," Energy Engineering: J ournal of the Association of Energy Engineers, vol 90, no. 5 (1993).

Abstract: This paper lists the sources of indoor pollutants that contribute to SBS and Building Related IIIness (BRI). It discusses the importance of testing for Volatile Organic Compounds (VOC) and microbes and describes the collection and analytical testing methods. There is a discussion of testing techniques including air sampling, bulk and surface sampling, morphological types, and VOC testing. There is no single agency or organization with oversight for VOCs, therefore, several occupational standards exist. Future testing techniques may indude biosensors that can screen samples for trace residues on-site, indicating when a full laboratory analysis is necessary. The authors condude by recommending baseline studies be conducted after building commissioning, after renovation or reconfiguration, or after a catastrophe. A comparison can then be made later if problems or complaints arise. Obtaining the most energy efficient buildings relies on the ability to control pollutants to support occupant health, comfort, and productivity.

Woods, J ., S. Arora, and N. Sensharma, "Indoor Environmental Diagnostics: Evolution of a Systematic Approach," College of Architecture and Urban Studies, Virginia Polytechnic Institute and State University, VA (March 22-25, 1994).

Abstract: The problem with methods currently used to diagnose indoor environments is that they do not detect faults directly. This discussion introduces an advanced approach to diagnostics that focuses on detection of compliance/noncompliance with a predetermined set of criteria that includes human response, exposure, system performance, and economics. The procedure can be used for a complex of buildings as well as multiple zones within a single building. 
Woods, J ., S. Arora, N. Sensharma, and B. Olesen, "Rational Building Performance and Prescriptive Criteria for Improved Indoor Environmental Quality," Proceedings of I ndoor Air vol 1 (1993).

Abstract: Current building codes and regulations inhibit or are inadequate to provide a building with occupant comfort or prevent deleterious conditions. Performance criteria based on human response and exposure el ements are better suited for this task. This paper proposes a method of development for performance criteria; and then translates them into prescriptive criteria for use in design, specification, construction, and occupation.

Woods, J ., and N. Boschi, "Evolving Concepts of Continuous Degradation and Continuous Accountability," Virginia Polytechnic Institute and State U niversity (n.d.).

Abstract: During the last decade the idea of "sick" or "healthy" buildings has been introduced and refined in definition throughout conferences regionally, nationally, and internationally. This document describes the evolving state of the concepts of "continuous degradation" and "continuous accountability." A survey of eleven litigation cases helps explain the idea of these concepts and presents issues for consideration in practice.

\section{Hawthorne Effect}

Note: These studies are cited for their potential relevance to building occupant comfort and productivity surveys. They address the Hawthorne Effect, a skewing of survey results due to the act of surveying itself.

Granberg, Donald, and Soren Holmberg, "The Hawthorne Effect in Election Studies: The Impact of Survey Participation in Voting," British J ournal of Political Science, vol 22, no. 2 (1992).

Abstract: This article discusses the Hawthorne Effect in its application to people voting. A study was done in Sweden in which a sample population was chosen and interviewed about politics and election practices prior to a governmental election. It was discovered that interviewing people about the election prior to the act of voting increased the voter turnout. A higher number of people voted after being interviewed than those from the group where no interview took place. The study proposes interviewing, even if it is only such questions as whether or not one intends to vote at all. It suggests that clever ways to interview become standard so that voter turnout increases.

J ones, Stephen R. G., "Was There a Hawthorne Effect?," The American J ournal of Sociol ogy, vol 98, no. 3 (1992). 
Abstract: The Hawthorne Effect has been a staple of social studies since the late 1920s. This article challenges the birth of this effect at the Western Electric Hawthorne Plant. The contention is whether or not there was indeed a Hawthorne Effect at the Hawthorne Plant. The article argues whether the experimental changes produced an effect that could be regarded as a part of the experiment. Data was used from the original Relay Test Room to conclude that there was no Hawthorne Effect at Hawthorne.

Parsons, H.M., "What Happened at Hawthorne?," Science, vol 183, no. 4128 (1974).

Abstract: This article reviews the procedures and experiments of the Hawthorne Works of the Western Electric Co., in Cicero, IL. In experimental research, the Hawthorne Effect is the unwanted effect of the experimental operation itself. The experiments consisted of $24-$ not 13 , as was believed - periods in which the overall response rate rose to an asymptotic level near the end. However, rates did not always rise when a condition changed. This presumption led to a myth that any change resulted in faster work. Rates also rose without the change of conditions. Rates tended to rise within conditions. Other myths about Hawthorne are also discussed. Under new examination, the Hawthorne Effect could be redefined as the confounding that occurs if experimenters fail to realize how the sequences of subjects' performance affect what the subject will do.

Sonnenfeld, J effrey A., "Shedding Light on the Hawthorne Studies," J ournal of Occupational Behavior, vol 6, no. 2 (1985).

Abstract: The Hawthorne Studies on social influences in the workplace have weathered a decade of scholarly attack. Hawthorne critics have generally misunderstood or misrepresented the most ideological and methodological presumptions of this pioneering research, which was intended to generate - not verify - hypotheses. This artide reviews the decades of controversy within the historical context of the discipline of organizational behavior. Original research records and recent interviews with the actual study participants support the validity and importance of the original research reports. 


\section{List of Acronyms}

ANSI American National Standards Institute

ARD acute respiratory disease

AR Army Regulation

ASHRAE American Society of Heating, Refrigerating, and Air conditioning Engineers

BRI building-related illness

DAPP Department of the Army Productivity I mprovement Program

DoD Department of Defense

DoE Department of Energy

DSM demand side management

EPRI Electric Power Research Institute

HVAC heating, ventilation, and air conditioning

IESNA Illuminating Engineering Society of North America

IAQ indoor air quality

IFFM indirect fluorescent furniture mounted

IFMP International Facility Management Program

LCS lighting comfort scale

LPD lighting power density 
MCS multiple chemical sensitivity

O\&M operations and maintenance

OLS officelighting survey

OQ occupant questionnaire

POE post-occupancy evaluation

SBS sick building syndrome

VAV variable air volume

VDT visual display terminal

VOC volatile organic compounds

WBM West Bend Mutual (insurance company) 
USACERL DISTRIBUTION

Corelist. 